\title{
Effects of Flexible Working Method on Employee Performance: An Empirical Study in Turkey
}

Erkut Altindag* and Funda Siller

Beykent University, Turkey

*Corresponding author: Erkut Altindag, Beykent University, Turkey, Tel: +090 212 867-55-74; Fax: +090 212 867-55-76; E-mail: erkutaltindag@beykent.edu.tr

Received date: April 15, 2014, Accepted date: August 22, 2014, Published date: September 1, 2014

Copyright: (c) 2014 Altindag E, et al. This is an open-access article distributed under the terms of the Creative Commons Attribution License, which permits unrestricted use, distribution, and reproduction in any medium, provided the original author and source are credited.

\begin{abstract}
Flexible working methods have become more popular, because they increase employees' quality of life. The number of Turkish firms that support flexible working models and help employees coordinate their work and personal life better are increasing, because employers consider their employees' personal lives as more important. Changes in sectoral scope also played an important role in creating flexible working methods. For instance, the service sector's need to support long-term projects in shipping, banking, telecommunication, press, and oil led to new work processes to focus on customer satisfaction while introducing more flexible working methods. This study presents the effects of flexible working methods on employee performance. It found that flexible working models are very precious for the improvement of and the sustainability of employee performance. According to the results many of flexible methods factors including job's suitability for flexibility, job loyalty and attitude towards flexible working hours directly affect the employee performance.
\end{abstract}

Keywords: Flexible working methods; Work satisfaction; Living conditions; Motivation; Employee loyalty; Employee performance

\section{Introduction}

An increasingly global business context, new technologies, national and global economic crises, rising unemployment and increased competition have all contributed to the need for changing working methods. These changes became known as "flexibility concept," and since the 1970s, people-oriented approaches have become part of business life. Businesses have created innovative working models to adapt to changing conditions to maintain their competitive advantage and to lead their workforce to better levels of productivity.

Today, businesses are expected to treat employees such that they are satisfied with their work and the business they work for. Businesses aim to retain their qualified workforce and to keep pace with changing business practices. Businesses that concentrate on providing employee satisfaction have a competitive advantage, because they have devoted employees. That brings along motivation and productivity, allowing the businesses to make a difference and to be a preferred employer for qualified employees at the same time.

On the other hand, job creation and the management of unemployment is also an important aspect today. The main target of creating new work models and employment types is to promote employment and eliminate unemployment. Positive results for employees' personal lives are also more and more being considered. For example, flexible working could potentially eliminate traffic problems for employees who previously had to face dense traffic in their daily commutes, especially in big cities. Increased work satisfaction becomes possible when employees have more flexibility to schedule their spare time outside of work and bring fewer personal concerns to their working environment. The reduction of employees being late, employees who are not exhausted, employees focused on their work when present, and their devotion to their work significantly increase how smoothly a business can be run. In this context, the topic emphasized in this research was the effects of introducing the flexible working model on employee performance.

\section{Literature Review and Hypotheses}

\section{Flexibility concept}

Flexibility is not a new concept. In fact, various working methods of the past and of today can be considered flexible working. Flexibility can be looked at from viewpoint of laborers, professional employees, and employers. Moreover, a number of factors require flexible working, such as increasing competitive pressure, technological changes, changes in sectoral structure, convenient working hours, and unemployment $[1,2]$.

According to a publication of the Metal Industrialists Union of Turkey (MESS), Flexibility and Flexible Working, "businesses must renew themselves continuously because of continuously changing economic and industrial environment". This is why now businesses are expected to focus on diversity and complexity instead of standardized structures, simplicity instead of size, liquidity and openness instead of normativeness and sternness, and flexibly adapting to change instead of stagnation. These expectations are defined as "flexibility" $[3,4]$. According to this definition, flexibility is, in short, the ability to adapt to environmental changes. In other words, the ability of employees and businesses to most efficiently adapt to changing business environments. Flexibility in working time is referred to as "a significant and efficient means for adapting to fluctuations." New business concepts and modern regulations support flexible working systems worldwide [5].

\section{Appearance of Flexibility and Search for Flexibility}

While the concept of flexible work times is not new, flexibilization of work times is continuously gaining importance. This will be even 
more so in the coming years for various reasons. For example, advances in technology require new working methods and the adjustment of work hours to these changed working methods. To summarize, the reasons for increased flexibility in work time are: the necessity to increase and maintain competitiveness, the necessity of switching to flexible production due to international competition, and advances in technology. Developments in technology allow some more injury-prone jobs to be taken over by machines. As a result, employees have more spare time and are more creative at work. When evaluated from the viewpoint of the business, it is important to adapt work schedules in the business with investments made in technology, according to the machine's operating capacity and operating time. Flexibility of working times is important not only for the business but also for employees, because it enables them to manage their own time. Developing industrial countries aim to diminish unemployment both by creating flexible working hours and by shortening working hours, an approach that seems rather simple and suitable economically [6].

\section{General reasons of using flexible methods}

Economic Crisis and Unemployment: Increasing economic immobility and unemployment because of the crisis in the petroleum sector that occurred in the 1970s was an important factor in the spread of flexible working [7].

Technological Developments: Technological developments have an important place in the flexibility concept. Technology advanced rapidly after the economic crisis of the 1970s and the use of computercontrolled systems in production became widespread [8]. In this period, the labor market was transformed by the use of information communication technology, and the need for knowledge workers with the ability to adapt to change and development increased [9].

Globalization and Competition: Another significant finding of flexibility research is that economies go beyond their national frameworks, and in parallel to that, competition becomes gradually more international [10].

Deregulation is not the synonym for "flexibilization." Deregulation, the reduction of hectoring norms, has a flexibilizing effect, because it leaves more room for flexibility in work contracts. However, the reverse is not always true. In fact, flexibility is only possible with numerous rules [11]. Flexible working often means working off the books especially in developing countries such as Turkey. Flexible working is a product of development in the fields of information and communication. Moreover, flexible working makes it possible for the employee to have more spare time for himself. However, flexible employment and flexible work methods create an unsecure and unsteady environment for the worker, because the work relationship is often skewed in favor of the employer, reducing the protection of the worker [12]. The main idea of the concept of flexibility is to express flexibility in different ways, remaining open to the ability to adapt to change and to external factors. In this respect, flexibility is a determining factor during phases of dramatic change [13].

\section{Relationship between motivation and flexible working systems}

According to Akdemir [14], motivation can be defined as "fomenting individuals towards a specific purpose and specifying variables that may be influential in fomentation." According to the statement of Yankellovich [15], which is discussed as a different view on the relationship between motivation and flexible working methods, the number of people who feel satisfaction and self-realization by means of working is not great. It was indicated that working is not deemed significant by most people. Fomenting people to working life requires prioritizing non-material means as well as providing material resources. In this case, flexible management applications that allow employees to spend less time at work should be introduced. Lu et al. [16] find that flexibility has a consistently positive effect for work outcomes, but an exacerbating effect for feelings that family life interfered with work.

\section{Effect of flexible working systems on physical working conditions}

Technological developments and changes affect people psychologically in work life and the interaction is assessed as positive in terms of increasing the quality of work, but it is assessed as negative in terms of physical working conditions. Being able to adapt to technological development and to advance consciously through its utilization are important. Technological innovations may have negative consequences for the business and the employee when misused or used outside of its scope. For example, a newly purchased device can create more noise, light, or heat in the work environment. When approached in terms of physical conditions, this case rapidly affects employees' working lives. In such a case, being able to employ people with flexible working methods allowing them to spend less time at the work place would be rather healthy.

Main hypothesis (HA): Flexible work hours increase employees' working performances by affecting their work and life satisfaction and their organizational loyalty directly and positively.

H1: "Work Satisfaction" percipience towards the flexible working model affects employees' performance directly and positively.

H2: "Suitability of the Work to Flexibility" percipience towards the flexible working model affects employees' performance directly and positively.

H3: "Attitude towards Flexible Hours" percipience towards the flexible working model affects employees' performance directly and positively.

H4: "Satisfaction" percipience towards the flexible working model affects employees' performance directly and positively.

H5: "Organizational Loyalty" percipience towards the flexible working model affects employees' performance directly and positively.

H6: "Negative Effect of Work" percipience towards the flexible working model and employee performance have a negative relationship between.

H7: "Devotion to Work" percipience towards flexible working model affects employees' performance directly and positively.

\section{Methodology}

\section{Research goal}

The goal of this study is to measure the effects of the flexible working method on employee performance. Relationships between flexible working hours and work satisfaction, suitability of work to flexibility, attitude against flexible working hours, negative effect of the job, satisfaction, organizational loyalty, devotion to work, and work performance were examined. The study population included 
employees working in various sectors across Turkey, and 200 individuals participated in the survey.

The survey was conducted online via the survey.com website. A link was created for the survey form and sent to employees asking them to participate. The data collected were evaluated via survey.com using Microsoft Excel and SPSS 17 (Statistical Package for Social Sciences) software, and the hypotheses were evaluated using regression and multi-correlation analysis.

If the test or method of a research model is reliable, it will provide reproducible, consistent results. The survey conducted is not reliable if it yields different results when applied to different situations or when evaluated by different participants. Reliability is generally assessed by associating two observed viewpoints. For instance, the same test can be applied to the same person at two different times. If the test is reliable, the points obtained in the first situation will show a high correlation with the points obtained in the second situation. In these situations, it can be said that the test has test-retest reliability [17]. The test is said to be fully reliable if it results in the same measurements at every instance of measuring the feature to be measured.

\begin{tabular}{|l|l|}
\hline Cronbach's Alpha $(\boldsymbol{\alpha})$ & Number of Variables \\
\hline 0.903 & 44 \\
\hline
\end{tabular}

Table 1: General reliability statistics.

The reliability of the scale is measured by calculating Cronbach's alpha to determine general reliability: in Table 1, Cronbach's alpha value (parameter) is shown to be 0.903 . According to Nunnally [18], Cronbach's alpha should be at least 0.700 or higher for surveys in social sciences. General reliability of the scale is a concept that can be expressed as employees' participating in the survey understanding the questions correctly and responding to them in a common position, in the same direction. The value of 0.903 shows that the study is extremely reliable and we can move on to the next phase, factor analysis. Mathematical analysis of this process can be done by scaling both the benefits of flexible working methods and the performance scale. The reliability value for the 32 questions relating to the main flexible working factor as a single notion is determined to be 0.886 and that for the questions relating to the top performance factor (12 questions) to be 0.921 . No reliability problems occurred during both the general analysis and the sub-factor analyses at any level. The reliability parameters for all variables are shown in Table 2 .

\begin{tabular}{|l|l|l|l|l|}
\hline \multicolumn{2}{|l|}{ Flexible Working Factor } & \multicolumn{3}{l|}{ Performance Factor } \\
\hline $\begin{array}{l}\text { Cronbach's Alpha } \\
(\alpha)\end{array}$ & $\begin{array}{l}\text { Number } \\
\text { variables }\end{array}$ & $\begin{array}{l}\text { Cronbach's Alpha } \\
(\alpha)\end{array}$ & $\begin{array}{l}\text { Number of } \\
\text { variables }\end{array}$ \\
\hline 0.886 & 32 & 0.921 & 12 \\
\hline
\end{tabular}

Table 2: Reliability analyses of the variables.

\section{Testing suitability of the factor analysis}

Factor analysis is conducted for reducing the number of variables by defining basic variables or factors based on a set of observed parameters. Each defined factor consists of variable sets relating to each other and measuring the same feature-that is, the relationship among the parameters. When different dimensions are involved, each basic variable or factor obtained by factor analysis expresses different dimensions. In short, a variable set that constitutes a factor measures the same dimension. The suitability of data gathered through sampling for factor analysis can be explained using the KMO (Kaiser-MeyerOlkin) parameter and the "Sphericity" test of Bartlett [19]. The focus of this experimental research is to assign variables used in the correct scale to the factors that they belong to. For the purpose of this study, detailed factor analyses were conducted using SPSS program and two main basic variables-the contribution of employees to flexible working hours and employee performance-which were dissociated from their sub factors. The most remarkable fact was that while flexible working hours alone divides seven sub factors, the employee performance variable is perceived as a single main factor. In KMO, the factor to be checked first in the factor analyses for both top factors, it is seen that the inner consistency ratios are of a high level. Factor loadings indicate a variable's relationship with its own factor and thus can be used to weigh the contributions of variables towards their own factors [20]. As expected, the employee performance questions included in one factor are perceived by participating employees to be in the same direction, which indicates that the 12 questions of the survey are based on the same structural soundness. All variables related to the other scale, flexible working, are separated into seven sub factors in total-job satisfaction, job's suitability to flexibility, attitude towards flexible working hours, satisfaction, organizational loyalty, job's negative effect to satisfaction, and loyalty to the job.

The fact that seven sub factors are obtained from the variables of 32 survey questions shows that various factors influence employees' opinions about their work. The most remarkable factor in these analyses was the sixth sub factor, which includes the statements "I find my job quite wearing" and "My work environment makes me stressed." Owing to these two questions, which were evaluated on a reverse scale under normal conditions, forming a sub factor on their own, no further analysis was needed. Further, the inclination to accept any task and put in extra effort to contribute to the institution is rationally representative of the seventh factor. Loading these two variables (which are significant only together) on a single factor indicates that the analysis is realistic beyond related figures. In light of this information, the flexibility scale with seven different dimensions calls for correlation and regression analyses to be conducted in the next phase. Distribution of factor groups is shown in the following Table 3.

\begin{tabular}{|l|l|}
\hline Flexibility Factor Groups & Number of Questions \\
\hline Job Satisfaction & 3 \\
\hline Job's Suitability to Flexibility & 9 \\
\hline Attitude Towards Flexible Hours & 6 \\
\hline Satisfaction & 7 \\
\hline Organizational Loyalty & 3 \\
\hline Job's Negative Effect & 2 \\
\hline Loyalty to the job & 2 \\
\hline Performance Factor Groups & \\
\hline Employee Performance & 12 \\
\hline Total Number of Questions & 44 \\
\hline
\end{tabular}

Table 3: Distribution of factor groups. 
The correlation parameter explains the directions of variables and how they interact. It takes values between -1 and +1 . This parameter takes the value of zero if there is no interaction, 1 if there is a strong interaction, and -1 if there is a reverse and whole interaction. Further, the correlation parameter is generally indicated using the letter "r." Thus, we can show the correlation parameter with its inequality. The sample observation number (n) is quite significant when evaluating the parameter for intermediate values. In evaluations based on a high number of observations, even a correlation parameter as low as 0.25 could be deemed significant [21]. Correlation parameters are shown in the following Table 4 .

\begin{tabular}{|l|l|l|l|l|l|}
\hline $\begin{array}{l}\text { High } \\
\text { Negative } \\
\text { Relation (-) }\end{array}$ & $\begin{array}{l}\text { Medium } \\
\text { Negative } \\
\text { Relation (-) }\end{array}$ & $\begin{array}{l}\text { Weak } \\
\text { Negative } \\
\text { Relation (-) }\end{array}$ & $\begin{array}{l}\text { Weak } \\
\text { Positive } \\
\text { Relation } \\
(+)\end{array}$ & $\begin{array}{l}\text { Medium } \\
\text { Positive } \\
\text { Relation } \\
(+)\end{array}$ & $\begin{array}{l}\text { High } \\
\text { Positive } \\
\text { Relation } \\
\mathbf{( + )}\end{array}$ \\
\hline$-1 \leq r<-0.8$ & $\begin{array}{l}-0.8 \\
r<-0.5\end{array}$ & $-0.5 \leq r<0$ & $0<r \leq 0.5$ & $0.5<r \leq 0.8$ & $0.8<r \leq 1$ \\
\hline
\end{tabular}

Table 4: Correlation parameter table. Source: Güler et al. [22].

\section{Results}

The correlation values show that organizational loyalty, a sub factor of flexible working, has a direct, positive effect on employee +performance, with a value of $0.410^{* *}$. In other words, employees think that the organization they work for is a perfect place for working and are proud of working there, and they reflect these ideas in their performance as a direct and strong effect. Job loyalty, another sub factor of flexible working, has strongly contributed to employee performance with a correlation value of $0.326^{* *}$. In this sub factor, employees are willing to put in higher effort than they are expected to for contributing to the organization's success. Moreover, employees are willing to take on any job to remain in the organization, and the relation between these factors and performance has been analyzed to be positive and of medium strength.

Job satisfaction has a correlation value of $0.294^{* *}$, showing that even if employees switch to another company, they still prefer doing the same job, are well satisfied with their work, and do their jobs gladly most of the time. This has a positive effect on performance. Attitude towards flexible working hours has a positive effect on performance, with a value of $0.256^{* *}$. In this factor, according to employees, flexible working hours provide an opportunity to rest and having flexible working hours motivates employees. Meanwhile, changing working hours suitable for work affects job loyalty in a positive way, and the flexible working method has positive results on employees' satisfaction with arrangements for child care and household tasks, helps employees have more time for themselves, and contributes positively to job performance.

\begin{tabular}{|c|c|c|c|c|c|c|c|c|c|}
\hline & & $\begin{array}{l}\text { Job } \\
\text { Satisfaction }\end{array}$ & $\begin{array}{l}\text { Job's } \\
\text { suitability to } \\
\text { flexibility }\end{array}$ & $\begin{array}{l}\text { Attitude } \\
\text { towards } \\
\text { Flexible } \\
\text { Hours }\end{array}$ & Satisfaction & $\begin{array}{l}\text { Organization } \\
\text { al Loyalty }\end{array}$ & $\begin{array}{l}\text { Job's } \\
\text { Negative } \\
\text { Effect }\end{array}$ & Job Loyalty & $\begin{array}{l}\text { Employee } \\
\text { Performance }\end{array}$ \\
\hline $\begin{array}{l}\text { Job } \\
\text { Satisfaction }\end{array}$ & $\begin{array}{l}\text { Pearson } \\
\text { Correlation }\end{array}$ & 1 & $.502^{* *}$ & $.373^{* *}$ & $.493^{* *}$ & $.763^{* *}$ & $-265^{* *}$ & $.590^{* *}$ & $.294^{* *}$ \\
\hline $\begin{array}{l}\text { Job's } \\
\text { suitability to } \\
\text { flexibility }\end{array}$ & $\begin{array}{l}\text { Pearson } \\
\text { Correlation }\end{array}$ & $.502^{* *}$ & 1 & $.442^{* *}$ & $.376^{* *}$ & $.425^{* *}$ & -0.067 & $.326^{* *}$ & $.207^{* *}$ \\
\hline $\begin{array}{l}\text { Attitude } \\
\text { towards } \\
\text { Flexible } \\
\text { Hours }\end{array}$ & $\begin{array}{l}\text { Pearson } \\
\text { Correlation }\end{array}$ & $.373^{* *}$ & $.442^{* *}$ & 1 & $.227^{* *}$ & $.421^{* *}$ & 0.012 & $.351^{* *}$ & $.256^{* *}$ \\
\hline Satisfaction & $\begin{array}{l}\text { Pearson } \\
\text { Correlation }\end{array}$ & $.493^{* *}$ & $.376^{* *}$ & $.227^{* \star}$ & 1 & $.396^{* *}$ & -0.105 & $.553^{* *}$ & $.200^{* *}$ \\
\hline $\begin{array}{l}\text { Organization } \\
\text { al Loyalty }\end{array}$ & $\begin{array}{l}\text { Pearson } \\
\text { Correlation }\end{array}$ & $.763^{* *}$ & $.425^{* *}$ &, $421^{* *}$ & $.396^{* *}$ & 1 & $-.180^{*}$ & $.713^{* * *}$ & $.410^{* *}$ \\
\hline $\begin{array}{l}\text { Job's } \\
\text { Negative } \\
\text { Effect }\end{array}$ & $\begin{array}{l}\text { Pearson } \\
\text { Correlation }\end{array}$ & $-.265^{* *}$ & -0.067 & 0.012 & -0.105 & $-.180^{*}$ & 1 & -0.093 & -0.021 \\
\hline Job Loyalty & $\begin{array}{l}\text { Pearson } \\
\text { Correlation }\end{array}$ & $.590^{* *}$ & $.326^{* *}$ & $.351^{* *}$ & $.553^{* *}$ & $.713^{* *}$ & -0.093 & 1 & $326^{* *}$ \\
\hline $\begin{array}{l}\text { Employee } \\
\text { Performance }\end{array}$ & $\begin{array}{l}\text { Pearson } \\
\text { Correlation }\end{array}$ & $.294^{* *}$ & $.207^{* *}$ & $.256^{* *}$ & $.200^{* *}$ & $.410^{* *}$ & -0.021 & $.326^{* *}$ & 1 \\
\hline
\end{tabular}

Table 5: Correlation Analysis.

The factors job's suitability to flexibility $\left(0.207^{* *}\right)$ and satisfaction $\left(0.200^{* *}\right)$ affect employee performance positively, although not at a high rate. From Table 5, it can be seen that there is a high correlation $\left(0.713^{* *}\right)$ between organizational loyalty and job loyalty; both these factors have a positive correlation with employee performance. According to the data obtained, employees tell their friends that their work place is a perfect environment for work, that they are proud of being a part of it, and that they can reach their full potential at work. For job loyalty, it is seen that employees are willing to put in high amount of efforts to contribute to their organization's success and are willing to undertake any duties to be able to remain there. On the other hand, the factor job's negative effect has a negative impact on 
Page 5 of 7

employee performance (-0.021). Work environments that cause stress for employees affect performance negatively. A significant and positive correlation $\left(0.713^{* *}\right)$ between organizational loyalty and job satisfaction is observed. Further, employees with high organizational loyalty have positive opinions about their job satisfaction. The relationship between job satisfaction and organizational loyalty is strengthened when employees wish to do the same job even after changing their office, are satisfied with their work, and do their job gladly most of the time. Again, these two factors had a positive effect on employee performance. Employees in businesses that have adopted flexible working hours had positive opinions about both organizational loyalty and job satisfaction. In the correlation analysis, the correlation between job loyalty and satisfaction has a value of $0.553^{* *}$. An increase in the level of employee satisfaction affects their loyalty to the organization and work performance in general. From the correlation table, it is clear that hypotheses developed before commencing the research are quite valid.

Regression analysis is used to measure the relationship among two or more variables. Regression uses equations to show mathematical relations between a dependent variable and independent variables to explain the dependent variable. Regression analysis is beneficial when two variables are related to each other and a systematic change is observed in one of them when the other is changed. The analysis conducted to derive mathematical expressions for the relation between two variables is called regression and the equation that represents this relation is called the regression equation. We tried to calculate the instituted regression model by using observed values from the study sample. Thus, the values included in our model are approximations. A regression model involving analysis of one variable is called a simple regression, and in the case of two or more variables, it is called multiple regression.

In our study, multiple regression analysis was conducted using SPSS program after the correlation analysis. Results show that organizational loyalty is the strongest factor shadowing all the other independent variables. Particularly, with a 0.393 beta level (significance level below 1\%), organizational loyalty effects job performance directly, and $18.4 \%$ of changes in job performance are determined by organizational loyalty. Moreover, the regression analysis results show that organizational loyalty is more important than the effects of other factors (job satisfaction, job's suitability to flexibility, attitude towards flexible working hours, satisfaction, job's negative effect, and job loyalty). It is clear that organizational loyalty is the only factor that affects employee performance. We believe that organization management would be able to achieve better employee performance, efficiency, and profitability by shaping the organizational structure in light of this information. Table 6 explains about abstract of Model.

\begin{tabular}{|l|l|l|l|l|}
\hline Model & $\mathbf{R}$ & R Square & $\begin{array}{l}\text { Corrected } \\
\text { Square }\end{array}$ & Approximate \\
\hline 1 & $.429 a$ & 0.184 & 0.152 & 0.71951 \\
\hline
\end{tabular}

Table 6: Abstract of Model. 'a '=Independent Variables: Job Loyalty, Job's Negative Effect, Job's Suitability to Flexibility, Attitude Towards flexible Hours, Satisfaction, Job Satisfaction, Organizational Loyalty Factor.

The details of Table 7 are discussed in the conclusion section. We statistically show that when employees adopt and accept organizational goals and vision, work in harmony with their team members, and devote their full potential to the organization, their work performance is positively affected.

\begin{tabular}{|l|l|l|l|l|l|}
\hline \multirow{2}{*}{$\begin{array}{l}\text { Regression } \\
\text { Model }\end{array}$} & \multicolumn{2}{|l|}{$\begin{array}{l}\text { Unstandardized } \\
\text { Parameters }\end{array}$} & $\begin{array}{l}\text { Standardized } \\
\text { parameters }\end{array}$ & $\mathrm{t}$ & \multirow{2}{*}{ Sig. } \\
\cline { 2 - 6 } & $\mathrm{B}$ & $\begin{array}{l}\text { Standard } \\
\text { Deviation }\end{array}$ & Beta & \multicolumn{2}{|l|}{} \\
\hline (Fixed) & 4.609 & 0.28 & & 16.453 & 0 \\
\hline Job Satisfaction & -0.04 & 0.057 & -0.081 & -0.697 & 0.487 \\
\hline $\begin{array}{l}\text { Job's Suitability } \\
\text { to Flexibility }\end{array}$ & 0.008 & 0.053 & 0.013 & 0.152 & 0.879 \\
\hline $\begin{array}{l}\text { Attitude towards } \\
\text { Flexible hours }\end{array}$ & 0.053 & 0.042 & 0.1 & 1.264 & 0.208 \\
\hline Satisfaction & 0.022 & 0.044 & 0.044 & 0.493 & 0.622 \\
\hline $\begin{array}{l}\text { Organizational } \\
\text { Loyalty }\end{array}$ & 0.189 & 0.06 & 0.393 & 3.146 & 0.002 \\
\hline $\begin{array}{l}\text { Job's Negative } \\
\text { Effect }\end{array}$ & 0.015 & 0.03 & 0.035 & 0.494 & 0.622 \\
\hline Job Loyalty & 0.016 & 0.059 & 0.031 & 0.277 & 0.782 \\
\hline
\end{tabular}

Table 7: Model's parameter. Dependent variable: Employee performance.

In regression model, a few of the seven independent variables seemed to have more influence than others. When performance is considered the dependent variable, organizational loyalty is prominent and has a higher effect on performance than the other factors. In other words, the independent variable organizational loyalty rules out other independent variables, although they are proved a significant relationship in correlation analysis. The basic purpose of the regression analysis is to gauge which factors affect each other and to what extent. According to the results, organizational loyalty and performance are positively correlated in organizations that adopt a flexible working method. We also found that organizational loyalty leads to higher efficiency among employees and promotes employee loyalty. Nowadays, the demands and priorities of employees are gradually changing. Employees aim to live better, achieve faster promotions, and earn more. While they want to work in qualified positions, they prefer being comfortable outside of work. Working methods that will meet the employees' expectations and allow for a better work-life balance are now part of our lives. Flexible working is now commonly regarded as having positive effects by not only employees but also employers.

Flexibility has become more widespread as Fordism style manufacturing is losing its significance and the technical transformation of business processes through automation, information technology, the internet, and others is gaining importance. The multiple economic depressions of recent years have caused flexible working to become more prevalent. The purpose of flexible working methods is to adapt to changing conditions. Flexible working methods are preferred by employers to increase their compatibility to environment and intense competition and reduce their labor costs to survive under changing economic and business conditions. 
New working methods are preferred by organizations to gain competition advantage and affect employees' work-related attitudes through their benefits and inconveniences for employees. The attitudes of individuals towards new working models are positive because of improved convenience in their personal lives, which increases their job satisfaction and loyalty. It has become very important for businesses to retain qualified employees in the organization. Employees with a strong sense of organizational loyalty aim to fulfill their responsibilities at their best by putting in more effort. In sum, to develop employees with high organizational loyalty and retain them in the organization for a long time, it is important for organizations to adopt flexible working practices.

This study involved a 44-question survey on the effect of flexible working method on employee performance. The sample consisted of employees from businesses that have adopted flexible working methods. The survey aimed to gain values for the following variables: organizational loyalty, job satisfaction, motivation, job's suitability to flexibility, attitudes towards flexible hours, job loyalty, and job's negative effect, and the effects of the flexible working model on job performance. The survey was answered by 200 individuals in Turkey, and analyzed using SPSS program. In the survey, a flexible working scale with 32 questions was divided into seven sub dimensions and a performance scale with 12 questions was combined into a single factor. Multiple regression analysis was conducted to analyze the extent of the effect of flexible working methods on employee performance. The effects of the independent variables, job satisfaction, motivation, job's suitability to flexibility, attitude towards flexible working hours, job loyalty, job's negative effects, and organizational loyalty, on the dependent variable, performance, and the significance of these effects were examined. A total of 44 variables were evaluated, and the reliability value (Cronbach's alpha) was determined to be 0.903 .

To examine the main hypothesis of the study and to examine the direct or indirect effects of flexibility on performance, the relationships among the study variables were examined using correlation analysis. It was found that the employees of organizations that adopt flexible working practices have high organizational loyalty, and thus, their work performance is positively affected. Organizational loyalty has a direct and positive effect on employee performance with as correlation value of $0.410^{* *}$. We concluded that flexible working practices have a positive effect on work-life balance after conducting regression analysis by evaluating employees' positive attitudes towards flexible working conditions. Further, employers with a positive attitude towards flexible working hours improve employees' organizational loyalty and benefit from its positive effect on employee performance.

The analysis of other flexible working methods shows a significant and positive correlation between job satisfaction and organizational loyalty with a correlation value of $0.763^{* *}$. Moreover, survey results show a positive relationship between organizational loyalty and job loyalty with a correlation value of $0.713^{* *}$. In organizations where forming organizational loyalty is priority and employees' sense of loyalty is being developed, it is possible that other perceptions toward performance have a positive result. The correlations among the sub factors for flexible working, as mentioned above, show a significant relationship between organizational loyalty and job satisfaction. We can conclude that there is a positive relationship between a job's suitability to flexibility and organizational loyalty with a correlation of $0.425^{* *}$. Similarly, there is a positive relationship between attitude towards flexible hours and organizational loyalty, with a correlation value of $0.421^{* *}$, and between satisfaction and organizational loyalty, with a correlation value of $0.396^{* *}$.

Considering the demographic variables for the survey, the work experience categories of the employees participating in the survey were as follows: $1-5$ years (15\%), 6-10 years (43\%), 11-15 years (22\%), more than 16 years (20\%). Since the highest number of employees (43\%) has 6-10 years' experience, followed by $22 \%$ employees with $11-15$ years' experience and $20 \%$ with 16 years' experience, we can say that $85 \%$ of employees have been working for over 6 years. Further, organizational loyalty is created in organizations with flexible working methods. Besides, some organizational regulations should be implemented in businesses to benefit from the positive results of the flexible working model. As we mentioned previously, it is necessary to take measures against the negatives effects concerning employees, employers, and society that may occur as a result of such regulations and some flexible working concepts in the labor law.

\section{Conclusion}

Flexibility in business life is important for organizations to create employee loyalty. Moreover, flexible working regulations that are supported by shareholders (e.g., manager, colleagues, and employers) and have a positive effect on work-life balance are considered to enhance their sense of loyalty. The elements beneficial for the organization and employees-regulation, renovation, and development of work form, and work timings as per employee demands, requests, and desires-could be achieved by ensuring the support of all employees.

The following are suggestions and implications for managers and researchers based on our research results and they are shown in the Figure 1:

Providing flexible working regulations that help employees achieve work-life balance is significant for winning employees' devotion and loyalty to the organization.

It would be a big step for businesses to adopt flexible working methods to improve organizational loyalty. Many employees have admitted telling their friends that their organization is a very good place to work. Loyal employees have pointed out the importance of organizational loyalty by eliminating other perceptions and sub factors toward flexible working methods and stating that they are proud of being a part of their organization and think that they can realize their full potential there.

There is a positive relation between organizational loyalty and flexible working practices' positive effect on work-life balance. Nowadays, employees attach greater importance to work-life balance than they did in the past. This means that employees' organizational loyalty would be higher in organizations with flexible working practices.

Flexible working hours that allow employees to designate their time of arrival and departure at work is very appealing for employees, and employees of organizations allowing this have high organizational loyalty.

The attitudes of employees who think that flexible working methods have a positive effect on work-life balance and take advantage of this regulation would not lead to negative results. The regression analysis showed that a positive attitude towards flexible working practices has a direct and positive effect on employees' organizational loyalty. 


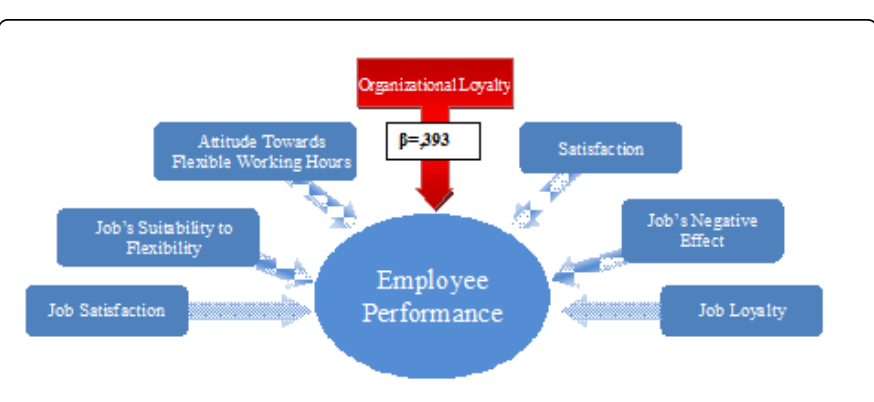

Figure 1: Suggestions and implications for managers and researchers.

Main hypothesis (HA): Flexible working hours improve employees' performance by affecting organizational loyalty directly and positively. This hypothesis is supported.

The correlation table shows that the hypotheses that were developed before beginning the research are valid. However, the regression analysis results do not support the hypotheses developed for other sub factors, because the relationship between flexible working and organizational loyalty was stronger than that among other sub factors. In sum, we examine the effects of flexible working practices, studied within the scope of this research, on employee performance and conclude that organizational loyalty leads to a significant increase in employee performance. Conducting statistical analyses using a larger sample without having sector limitations may provide more generalizable results in future studies. We also suggest that further research use the structural equality model or the AMOS program.

\section{References}

1. Celenk H, Atmaca M (2011) Flexible Work's Impact on Labor Costs and Competitiveness: An Application in Textile Sector, J Adm Sci 9: 275-305.

2. Lee D R (1996) Why is Flexible Employment Increasing? J Labour Res 17: 695-710.

3. Treu T (1992) Labour Flexibility in Europe. Int Labour Rev 131: 4-5.

4. Mess Türkiye MSS (1999) The book of Flexibility in public. Int Labour Rev 311: 145-148.
5. Sezgin E (2005) Labour Law and Labour Flexibility. J Labour Res 8: 211-250..

6. Ekonomi M (1994) Requirement of flexibilisation in Turkish Labor Law. Flexibility in Working Life Seminar. J Labour Res 7: 55-79.

7. Gediz B, Yalçınkaya H (2000) Employment-Unemployment in Turkey and Solutions: Flexibility Approach. J Labour Res, 6: 161-184.

8. Tregaskis O, Brewster C, Mayne L and Hegewisc A (1998) Flexible Working In Europe: The Evidence And The Implications. Eur J Work And Org Psy, 7: 61-78.

9. Horwitz FM, Smith DA (1998) Flexible Work Practices and Human Resource Management: A Comparison of South African And Foreign Owned Companies. The Int J Human Resource Manage 9: 590-607.

10. Yavuz A (2000) Flexibility and Turkey Recommendations for Working Life, Prof. Dr. N.Ekin'e Armağan. J Labour Res 38: 617-624.

11. Yunus AÇ (1993) Flexibility in Working Life, J Labour Res 6: 161-184.

12. Tozlu E (2011) Generally Flexible Work Systems and Comparison of telework and compressed work week. The Int J Human Resource Manage 4: 99-116.

13. Karakoyun Y (2007) Flexible Working Through Women's Labor Force Participation Rate and Employment Finn Increase: The Role of Iskur.Turkey.

14. Akdemir A (1996) Introduction to Business, II. Baskı, Turkey.

15. Yellovkovich D (1982) General Debate, Pyad X. Avrupa Kongresi Görüşmeleri Özeti, Dr. Ferhat Şenatalar, İstanbul.

16. Lu L, Kao S, Chang T, Wu H, Cooper C L (2008) Work/family demands, work flexibility, work/family conflict, and their consequences at work: A national probability sample in Taiwan. Int J Stress Manage 15: 1-21.

17. Şencan H (2005) Reliability and Validity of Social and Behavioral Measurement. 1st edition, distinguished Publisher, Ankara.

18. Nunnally JC (1978) Psychometric theory. 2nd ed. New York: McGraw Hill, USA.

19. Büyüköztürk Ş (2007) Additional Manual for Social Science Data Analysis, 7.Baskı, Pagem A. Ankara.

20. Ayranc1 ES (2010) Family-Power, Experience, Culture Impact on Family Scale and top managers of family businesses with a Family Member A Study on Relationship Between Overview for Managers, The Int J Human Resource Manage : 39: 335-358.

21. Yllmaz İ (2006) Correlation Analysis of the data-relations. Ankara University. Ankara.

22. Güler F (2005) Statistical Methods and Applications, Beta Basım Yayım, İstanbul, Turkey. 